\title{
Decrease of Alpha-fetoprotein in Patients with Cirrhosis Treated with Direct-acting Antivirals
}

\author{
Kelvin Nguyen ${ }^{1}$, Melissa Jimenez ${ }^{2}$, Nima Moghadam ${ }^{2}$, Crystal Wu ${ }^{2}$, Alex Farid ${ }^{2}$, \\ Jonathan Grotts $^{1}$, David Elashoff ${ }^{1,3}$, Gina Choi ${ }^{1,2}$, Francisco A. Durazo ${ }^{1,2}$, \\ Mohamed M. El-Kabany ${ }^{1,2}$, Steven-Huy B. $\operatorname{Han}^{1,2}$ and Sammy Saab*1,2
}

\begin{abstract}
${ }^{1}$ Departments of Medicine, the University of California at Los Angeles, Los Angeles, CA, USA; ${ }^{2}$ Departments of Surgery, the University of California at Los Angeles, Los Angeles, CA, USA; ${ }^{3}$ Departments of Biostatistics, the University of California at Los Angeles, Los Angeles, CA, USA
\end{abstract}

\begin{abstract}
Background and Aims: The lack of specificity has limited the role of serum alpha-fetoprotein (AFP) for hepatocellular carcinoma (HCC) screening among patients with cirrhosis related to hepatitis $\mathrm{C}$ virus (HCV) infection. We sought to examine whether AFP may decrease after achieving a sustained virological response (SVR) in patients with HCV-related cirrhosis. Methods: We performed a retrospective study of patients with HCV-related cirrhosis who were cured with direct-acting antiviral (DAA) therapy at the University of California, Los Angeles. Laboratory values, including serum AFP, were measured before and after completing the DAA treatment. Results: Fifty-six patients met the inclusion criteria, with median (interquartile range [IQR]) age of 67 (58-69) years and with $51.8 \%$ being male. All patients received DAA therapy without interferon. AFP decreased from median (IQR) $7.2(4.2-13.4) \mathrm{ng} / \mathrm{mL}$ before DAAs to $4.2(2.7-6.3) \mathrm{ng} / \mathrm{mL}$ at the end of treatment and $4.2(2.9-6.8) \mathrm{ng} / \mathrm{mL}$ at 12 weeks after treatment $(p<0.001)$. Model for end-stage liver disease (MELD), fibrosis-4 (FIB4), and aspartate transaminase (AST) to platelet ratio index (APRI) scores at baseline were not significantly associated with AFP reduction. On multivariate analysis, platelet count, AST and total bilirubin at baseline were significantly correlated to AFP reduction $(p=0.04,0.009$ and 0.04 , respectively). The higher the baseline AFP, the greater the reduction in AFP. There was no statistically significant correlation between baseline AFP and MELD, FIB4 or APRI scores. Conclusion: There was a significant decrease in AFP in patients with cirrhosis who achieved a SVR with DAAs. Given a reduction in AFP after DAA treatment, AFP should be further studied as a screening modality for HCC in patients with cirrhosis.
\end{abstract}

Keywords: Hepatitis C; Hepatocellular carcinoma; Screening; Direct-acting antivirals.

Abbreviations: AFP, alpha-fetoprotein; HCC, hepatocellular carcinoma; SVR, sustained viral response; DAAs, direct-acting antivirals; AASLD, American Association for the Study of Liver Diseases; IQR, interquartile range; EOT, end of treatment; MELD, model for end-stage liver disease; FIB-4, fibrosis-4; APRI, AST to platelet ratio index; IFN, interferon; HCV, hepatitis C virus; HBV, hepatitis B virus; HIV, human immunodeficiency virus; AST, aspartate transaminase; ALT, alanine transaminase; INR, international normalized ratio; Peg-IFN, pegylated interferon alpha-2a; RBV, ribavirin.

Received: 3 November 2016; Revised: 26 January 2017; Accepted: 1 February 2017

*Correspondence to: Sammy Saab, Pfleger Liver Institute, UCLA Medical Center, 200 Medical Plaza, Suite 214, Los Angeles, CA 90095, USA. Tel: +1-310-2066705, Fax: +1-310-206-4197, E-mail: SSaab@mednet.ucla.edu
Citation of this article: Nguyen $\mathrm{K}$, Jimenez $\mathrm{M}$, Moghadam $\mathrm{N}$, Wu C, Farid A, Grotts J, et al. Decrease of alpha-fetoprotein in patients with cirrhosis treated with direct acting agents. J Clin Transl Hepatol 2017;5(1):43-49. doi: 10.14218/JCTH. 2016.00057.

\section{Introduction}

Hepatocellular carcinoma (HCC) is considered one of the most lethal cancers, having a 5-year survival of approximately $15 \%$ and with most of cases diagnosed at advanced stage. ${ }^{1}$ In the United States, the incidence of HCC has almost tripled since the early 1980 s, largely believed to be a result of a cohort of patients with hepatitis $\mathrm{C}$ virus (HCV) developing advanced liver disease. ${ }^{2}$ Treatment of $\mathrm{HCC}$ is directly related to tumor burden and severity of underling liver disease. ${ }^{3}$ Early diagnosis through screening may lead to improved survival. ${ }^{2-7}$

The utility of utilizing alpha-fetoprotein (AFP) in the screening of patients with HCC has been controversial. It is not included in the current American Association for the Study of Liver Diseases (AASLD) screening guidelines because of concerns over its specificity. ${ }^{8-11}$ Viral infection with HCV can cause fluctuations in AFP that makes it difficult to differentiate between underlying liver disease and the development of HCC. ${ }^{12}$ AFP was seen to be elevated in non-HCC patients with HCV infection and normalized after antiviral treatment with interferon (IFN). ${ }^{13}$ IFN-based therapy that demonstrated a decrease in AFP values was limited to patients with compensated cirrhosis and normal cell indices. ${ }^{13-23}$

Over the past several years, all oral direct-acting antiviral (DAA) agents have replaced IFN for the treatment of $\mathrm{HCV}^{24-26}$ The advantages of DAAs are improved tolerability, safety and utility. ${ }^{24-27}$ Patients with advanced cirrhosis who were not candidates for antiviral therapy before could now be treated by DAAs. However, the impact of sustained virological response (SVR) on AFP achieved through DAAs in patients with cirrhosis is largely unknown. The hypothesis of our study is that achieving SVR in patients with cirrhosis leads to a significant decrease in AFP values. The implication is that AFP would be more specific for the diagnosis of HCC in patients with cirrhosis after HCV has been treated. 


\section{Methods}

\section{Study subjects}

Consecutive patients with cirrhosis and HCV treated with DAAs at the University of California Los Angeles (UCLA) Pfleger Liver Institute were identified through an administrative UCLA database. The study ran for 2.5 years, lasting from January 2014 to August 2016. Informed patient consent was required due to the study's retrospective nature. The UCLA Institutional Review Board approved the study.

Inclusion criteria included patients with HCV-related cirrhosis that were treated with DAAs with and without ribavirin (RBV). Patients must have shown obtainment of SVR at 12 weeks after treatment (SVR-12). Patients must have AFP at most 3 months before treatment with DAAs and after SVR12 has been obtained. Exclusion criteria include any organ transplant recipient, patients that were exposed to IFN during their treatment, patients lacking AFP data before treatment with DAAs or after obtaining SVR-12, patients with diagnosis of HCC before treatment, during treatment or within 6 months after treatment conclusion, or patients with coinfection with hepatitis $B$ virus (HBV) or human immunodeficiency virus.

We collected demographic information such as sex, age, race/ethnicity, coexisting liver diseases including nonalcoholic fatty liver disease, autoimmune hepatitis and alcoholic cirrhosis, and non-liver related comorbidities including cardiopulmonary diseases, end-stage renal disease on hemodialysis, non-HCC malignancy, and diabetes. Baseline laboratory, radiological, and histological results for confirmation of cirrhosis and evaluation of hepatic lesions, as applicable, were also recorded. Laboratory test results including measures of liver function markers, such as aspartate aminotransferase (AST), alanine aminotransferase (ALT), total bilirubin, prothrombin, international normalized ratio (INR), creatinine and AFP, were collected. Patients were also placed into two subgroups, either with follow-up AFP reduced from baseline (AFP reduction group) or follow-up AFP unchanged from or being higher than baseline AFP (non-AFP reduction group).

Liver disease severity was defined by MELD, FIB4 and APRI scores, and calculated as described. ${ }^{28-31}$ A diagnosis of splenomegaly was made radiographically with a spleen size of greater than $12 \mathrm{~cm}$ in any dimension. Portal hypertension was defined by a patient having one of the following diagnoses: splenomegaly, ascites, hepatic encephalopathy, or varices.

\section{Statistics}

Data are presented as median with interquartile range (IQR) or as number in group with percent of group based on the distribution of the data. Univariate analysis was performed using Wilcoxon signed rank test for paired continuous data. Correlation of lab values were computed using Spearman's correlation coefficients, and $p$-values from correlations were derived using the asymptotic $t$-approximation. A mixedeffects regression model with the likelihood ratio test was used to evaluate the time from treatment on laboratory values. Lab values were evaluated on the log scale in this regression model because of the heavy tailed distribution of the data. A logistic regression model was used to evaluate variables associated with a drop in AFP over time. Variables were included in the logistic regression model if they were significant on univariate analysis. Due to high correlation between AST and ALT, a model was fit using each variable separately and the model with the highest c-statistic was included in the results. All tests were two-sided, and a $p$-value below 0.05 indicated statistical significance. Statistical analyses were carried out using $\mathrm{R}$ statistical computing software (R Core Team, Vienna, Austria).

\section{Results}

\section{Demographics}

A total of 56 patients with HCV-related cirrhosis cured of the viral infection by all-oral DAAs were included in the study. The demographic characteristics of the study population are

Table 1. Patient demographic characteristics

\begin{tabular}{|c|c|}
\hline Variable & $n(\%)$ \\
\hline Age, median (IQR) & $67(58-69)$ \\
\hline \multicolumn{2}{|l|}{ Sex } \\
\hline Female & $27(48.2)$ \\
\hline Male & $29(51.8)$ \\
\hline \multicolumn{2}{|l|}{ Race/Ethnicity } \\
\hline White & $16(28.6)$ \\
\hline Black & $2(3.6)$ \\
\hline Hispanic & $6(10.7)$ \\
\hline Asian or Pacific Islander & $3(5.4)$ \\
\hline Other & $0(0)$ \\
\hline Unknown & $29(51.8)$ \\
\hline \multicolumn{2}{|l|}{ Non-liver medical history } \\
\hline \multicolumn{2}{|l|}{ Active cardiopulmonary disease } \\
\hline No & $50(89.3)$ \\
\hline Yes & $6(10.7)$ \\
\hline \multicolumn{2}{|l|}{ Recent non-HCC malignancy } \\
\hline No & $54(96.4)$ \\
\hline Yes & $2(3.6)$ \\
\hline \multicolumn{2}{|l|}{ Diabetes } \\
\hline No & $50(89.3)$ \\
\hline Yes & $6(10.7)$ \\
\hline \multicolumn{2}{|l|}{ Portal hypertension } \\
\hline Ascites & $17 / 54(31.5)$ \\
\hline Splenomegaly & $31 / 54(57.4)$ \\
\hline Hepatic encephalopathy & $11 / 54(20.4)$ \\
\hline Varices & $17 / 54(31.5)$ \\
\hline At least one of the above & $38 / 54(70.4)$ \\
\hline \multicolumn{2}{|l|}{ Antiviral treatment } \\
\hline OBV/PTV/r + DSV with RBV & $1(1.8)$ \\
\hline SOF/LDV with/without RBV & $41(73.2)$ \\
\hline SOF/RBV & $7(12.5)$ \\
\hline SOF/SIM & $7(12.5)$ \\
\hline
\end{tabular}

Abbreviations: IQR, interquartile range; OBV, ombitasvir; PTV, paritaprevir; $\mathrm{R}$, ritonavir; DSV, dasabuvir; SOF, sofosbuvir; LDV, ledipasvir; RBV, ribavirin; SIM, simeprevir. 
represented in Table 1 . The median (IQR) age of the cohort was 67 (58-69) years, and there was a similar representation of both men and women. Most patients were Caucasian. The most commonly used antiviral regimen was sofosbuvir/ ledipasvir (Table 1 ). The majority of patients were treatmentnaïve $(83.9 \%)$. The diagnosis of cirrhosis was confirmed by imaging in 44 patients $(78.6 \%)$ and by liver biopsy in $12(21.4 \%)$. Almost three-quarter of our patient cohort had some manifestation of portal hypertension, with the most common being the presence of splenomegaly. The median (IQR) follow-up for the study cohort was 12 (12-24) weeks after completing therapy.

\section{Lab variables before and after DAAs}

Baseline and follow-up laboratory values are shown in Table 2. At baseline, the median (IQR) AFP concentration was $7.2(4.2-13.4) \mathrm{ng} / \mathrm{mL}$. The median (IQR) albumin concentration and platelet count were $3.7(3.2-4.0) \mathrm{g} / \mathrm{dL}$ and 95 (60-132), respectively. Median (IQR) MELD, FIB4 and APRI values were 10.1 (7.5-12), $6.2(4.1-10.4)$ and $1.5(0.8-3.2)$, respectively.

There were statistically significant decreases in AFP, AST, ALT and alkaline phosphatase values over time, including before and after treatment (Table 3 ). There was a statistically significant decrease in AFP concentration at SVR-12 relative to baseline (coefficient $=-0.01$, SE 0.003, $p=<0.001$ ). Wilcoxon signed rank test showed the median (IQR) AFP within person difference of AFP at baseline minus AFP at 12 weeks was $-2(-5.5-0.4)(p<0.001)$. The median (IQR) AFP values before and at SVR-12 were $7.2(4.2-13.4) \mathrm{ng} / \mathrm{mL}$ and $4.2(2.9-6.8) \mathrm{ng} / \mathrm{mL}$, respectively $(p<0.001)$ (Table 2 and
Table 3. Mixed-effects model of lab values over time (coefficients are for time and lab values modeled on the log scale)

\begin{tabular}{lll}
\hline Lab value & Coef $(\mathrm{SE})$ & $p$ \\
\hline Alpha-fetoprotein, $\mathrm{ng} / \mathrm{mL}$ & $-0.016(0.003)$ & $<0.001$ \\
Platelet count, $10^{3} / \mathrm{\mu L}$ & $0.001(0.001)$ & 0.493 \\
Albumin, $\mathrm{g} / \mathrm{dL}$ & $0.001(0.001)$ & 0.4 \\
International normalized & $0(0)$ & 0.284 \\
ratio & & \\
Aspartate transaminase, U/L & $-0.014(0.002)$ & $<0.001$ \\
Alanine transaminase, U/L & $-0.015(0.003)$ & $<0.001$ \\
Total bilirubin, mg/dL & $-0.003(0.002)$ & 0.21 \\
Creatinine, $\mathrm{mg} / \mathrm{dL}$ & $0(0.001)$ & 0.504 \\
Alkaline phosphatase, U/L & $-0.003(0.001)$ & 0.001 \\
Hemoglobin, $\mathrm{g} / \mathrm{dL}$ & $0.001(0.001)$ & 0.595 \\
\hline
\end{tabular}

Fig. 1). The median AFP concentration remained low over time after achievement of SVR-12 ( $p<0.001)$ (Fig. 2). There was no correlation between baseline markers of liver disease severity and AFP values (Fig. $3 \mathrm{~A}-\mathrm{C}$ ). There was no statistically significant difference in the reduction of AFP per DAA strategy $(p=0.881)$. However, the greatest median (IQR) decrease in AFP was seen in patients treated with sofosbuvir and RBV (-6.15 (-7.12 - -5.17) ng/mL). Great decrease of AFP was seen in patients with higher baseline values of AFP. For instance, the median decrease of AFP was $-0.35 \mathrm{ng} / \mathrm{mL}, 2.25 \mathrm{ng} / \mathrm{mL}$, and $-7.1 \mathrm{ng} / \mathrm{mL}$ in patients with

Table 2. Laboratory values (median (IQR))

\begin{tabular}{|c|c|c|c|c|c|}
\hline Variable & Baseline $(n=56)$ & EOT $(n=40)$ & $12 \mathrm{w}(n=29)$ & $24 \mathrm{w}(n=20)$ & $48 \mathrm{w}(n=14)$ \\
\hline $\mathrm{AFP}, \mathrm{ng} / \mathrm{mL}$ & $7.2(4.2-13.4)$ & $4.2(2.7-6.3)$ & $4.2(2.9-6.8)$ & $5.1(2.8-7.5)$ & $3.7(3.1-4.9)$ \\
\hline Viral load, IU/mL & $\begin{array}{l}1200000 \\
(362000-4200000)\end{array}$ & $0(0-0)$ & $0(0-0)$ & $0(0-0)$ & $N A(N A-N A)$ \\
\hline $\begin{array}{l}\text { Platelet count, } \\
10^{3} / \mu \mathrm{L}\end{array}$ & $95(60-131.5)$ & $93(62-141)$ & $107(78-153)$ & $119(80-167.5)$ & $104.5(71-164)$ \\
\hline Albumin, $\mathrm{g} / \mathrm{dL}$ & $3.7(3.2-4)$ & $3.7(3.3-4.2)$ & $4(3.5-4.4)$ & $4(3.8-4.4)$ & $4(3.4-4.5)$ \\
\hline INR & $1.2(1.1-1.2)$ & $1.2(1.1-1.2)$ & $1.2(1.1-1.2)$ & $1.2(1.1-1.2)$ & $1.2(1.1-1.3)$ \\
\hline AST, U/L & $60(39.5-87.5)$ & $31(27-41.5)$ & $28(21-36)$ & $26(23-33)$ & $30(25.5-39.2)$ \\
\hline$A L T, U / L$ & $48(31.8-75)$ & $25(19.5-33)$ & $21(16-28)$ & $22(20-27)$ & $24.5(19.8-30.5)$ \\
\hline $\begin{array}{l}\text { Total bilirubin, } \\
\mathrm{mg} / \mathrm{dL}\end{array}$ & $0.9(0.6-1.7)$ & $0.9(0.5-1.6)$ & $0.7(0.5-1.3)$ & $0.7(0.5-1.3)$ & $1(0.4-1.8)$ \\
\hline $\begin{array}{l}\text { Serum creatinine, } \\
\mathrm{mg} / \mathrm{dL}\end{array}$ & $0.8(0.7-1)$ & $0.9(0.7-1)$ & $0.8(0.7-1)$ & $0.9(0.8-1)$ & $0.9(0.8-1)$ \\
\hline $\begin{array}{l}\text { Alkaline } \\
\text { phosphatase, U/L }\end{array}$ & $103(76-142.2)$ & $103(72.5-140.5)$ & $101(75-114)$ & $96(69-134)$ & $86(72.2-114.8)$ \\
\hline Hemoglobin, g/dL & $13.2(12.1-14)$ & $12.7(11.3-14.3)$ & $13(11.8-13.5)$ & $14.1(12.8-14.8)$ & $13.8(12.2-14.4)$ \\
\hline MELD & $10.1(7.5-12)$ & - & - & - & - \\
\hline FIB4 & $6.1(4.1-10.3)$ & - & - & - & - \\
\hline APRI & $1.5(0.8-3.2)$ & - & - & - & - \\
\hline Sodium, mmol/L & $139(137-141)$ & - & - & - & \\
\hline
\end{tabular}

Abbreviations: SVR12, sustained virological response at 12 weeks; AST, aspartate transaminase; ALT, alanine transaminase; AFP, alpha-fetoprotein; INR, international normalized ratio; MELD, model for end-stage liver disease; Na, sodium; FIB4, fibrosis-4; APRI, aspartate aminotransferase to platelet ratio index. 
Nguyen K. et al: AFP after SVR with DAAs

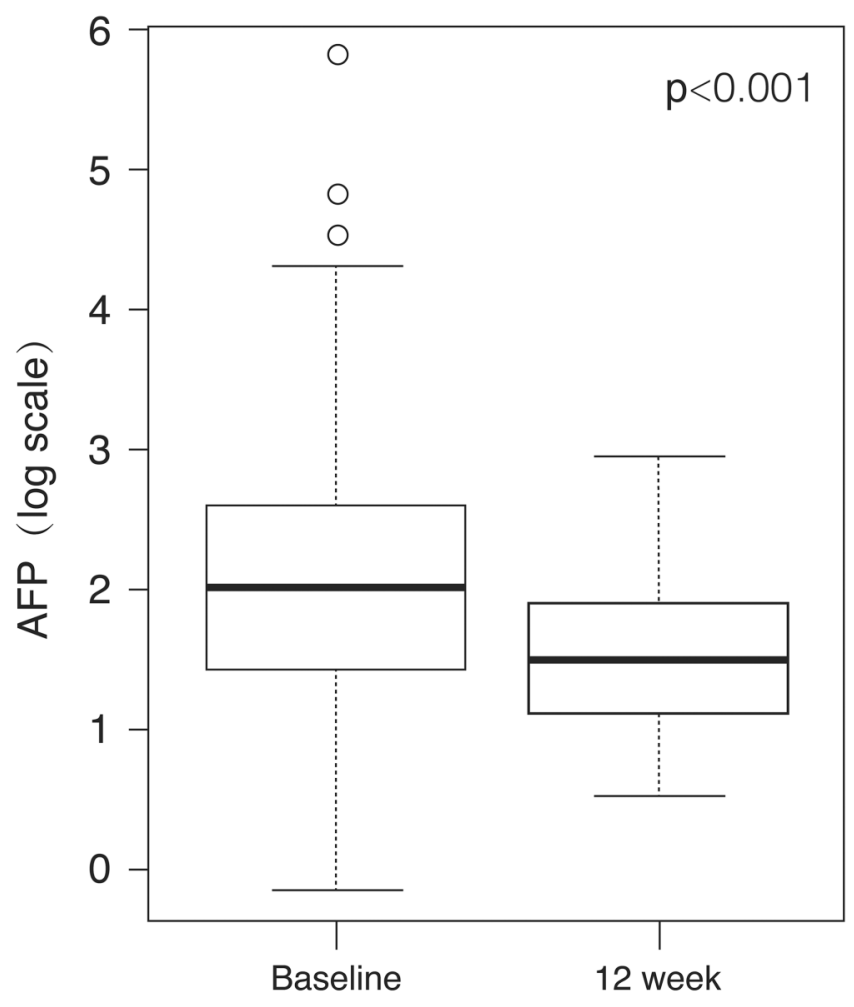

Fig. 1. Alpha-fetoprotein (AFP) levels pre- and post-treatment (at 12 weeks) in log scale.

baseline AFP values of $<5 \mathrm{ng} / \mathrm{mL}$, between 5 and $10 \mathrm{ng} / \mathrm{mL}$, and greater $10 \mathrm{ng} / \mathrm{mL}$, respectively (Fig. 4).

\section{Stratification according to reduction of AFP}

Of the 56 patients in the cohort, $46(82.1 \%)$ experienced a reduction in AFP. Upon subgroup analysis, when comparing AFP reduction and non-AFP reduction group the baseline AFP, AST, ALT, total bilirubin and platelet count were statistically significant factors that correlated to a reduction in AFP after DAA treatment in univariate analysis $(p=0.001,0.04,0.03$, 0.02 and 0.009 , respectively) (Table 4 ). After multivariate

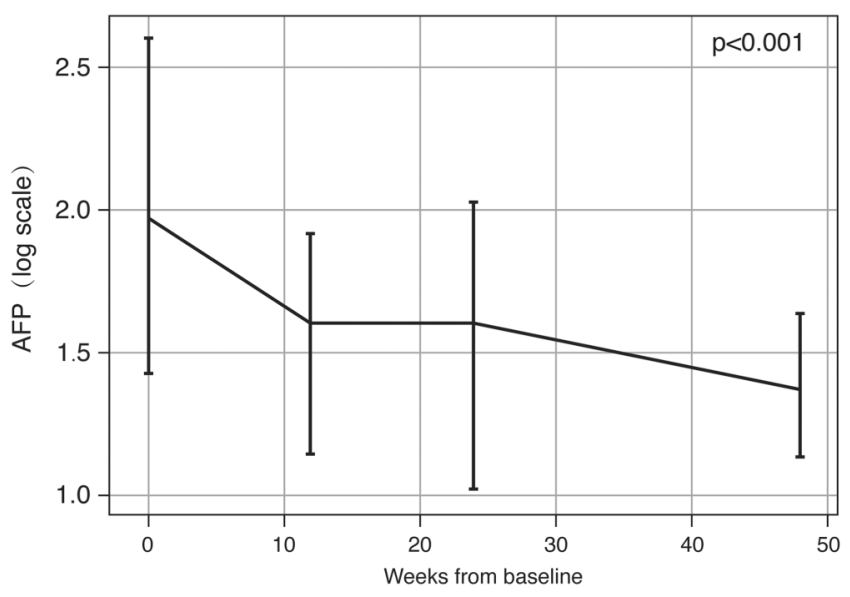

Fig. 2. Alpha-fetoprotein (AFP) reduction (median with IQR) over time.
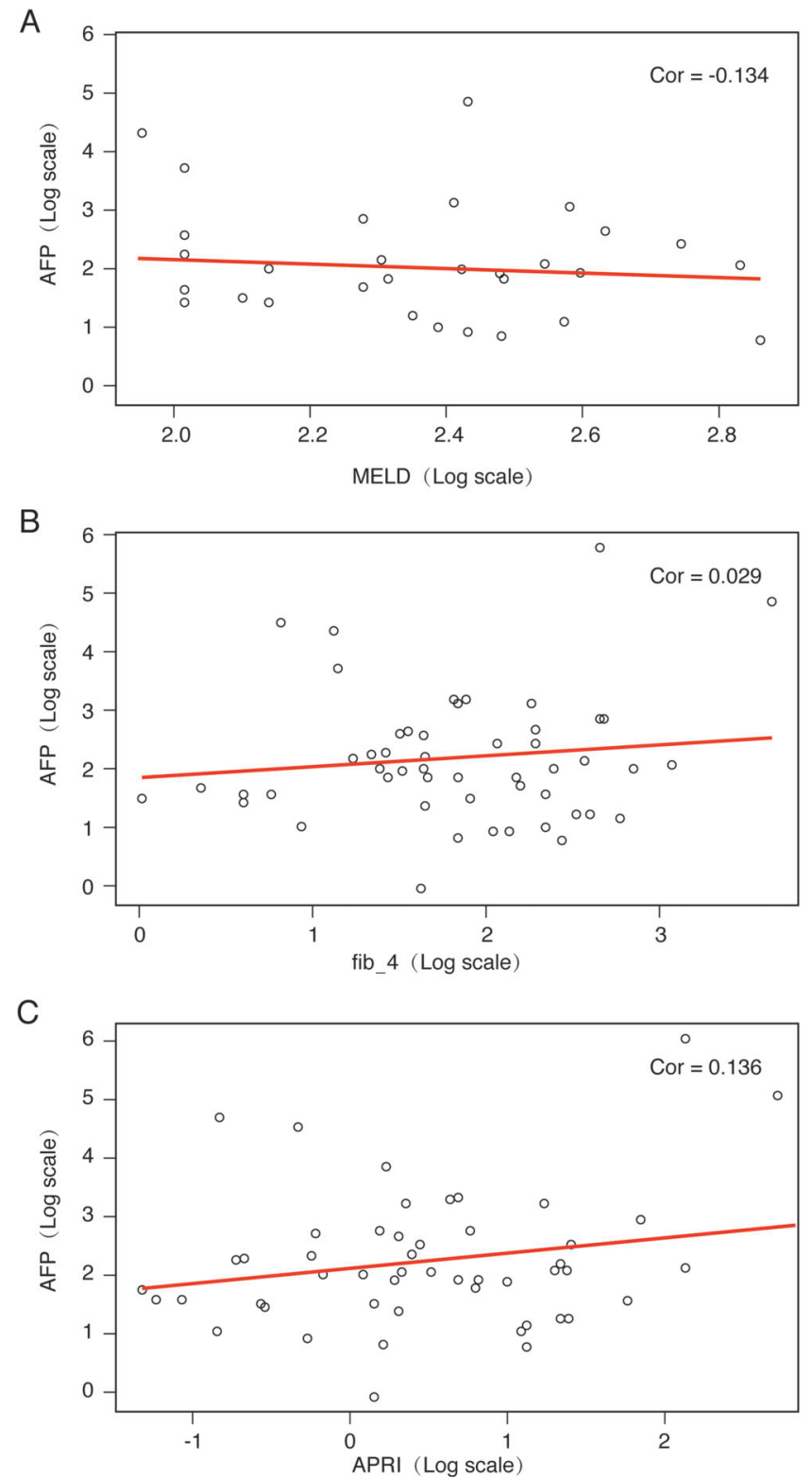

Fig. 3. Correlation between baseline alpha-fetoprotein (AFP) and severity of liver disease. A) Model of end-stage liver disease (MELD), B) Fibrosis-4 (FIB4), and C) Aspartate aminotransferase to platelet ratio index (APRI).

analysis, only AST, total bilirubin and platelet count were considered significant factors associated with AFP reduction ( $p=0.009,0.04$ and 0.04 , respectively) (Table 5).

\section{Discussion}

AFP is an embryo-specific protein, encoded by the AFP gene on chromosome 4 that is predominant during the first month of human embryonic life, synthesized in the yolk sac and liver in the first 1-2 months and subsequently mostly in the liver. ${ }^{32,33}$ Its role in adults is unknown but has been studied as a screening tool for patients with cirrhosis. Its utility has been limited because of poor specificity due to inflammatory effects which are the underlying cause of cirrhosis. In fact, studies 
Nguyen K. et al: AFP after SVR with DAAs

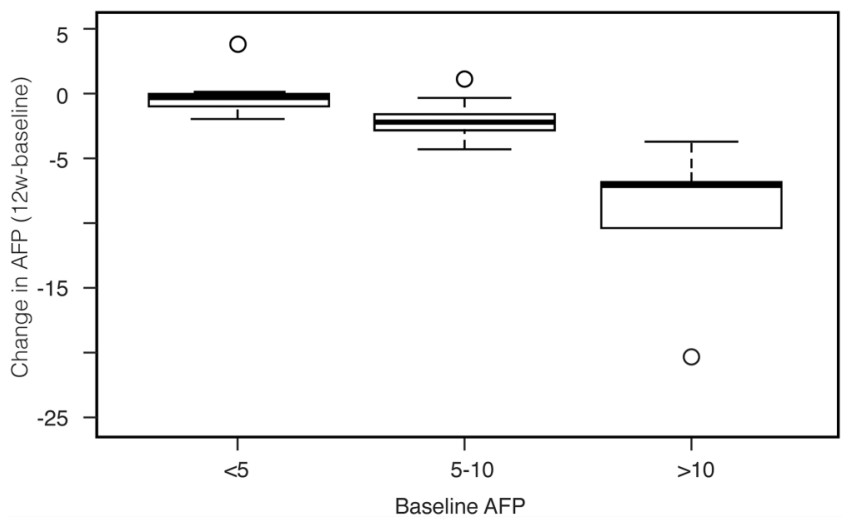

Fig. 4. Change in alpha-fetoprotein (AFP) according to baseline AFP. Change in AFP defined as the AFP difference between baseline and time of sustained viral response (12 weeks after completing antiviral therapy).

in suppressing viral replication in HBV and HCV infections have found significant decreases in AFP values. ${ }^{16,18,19,34-38}$ AFP may also have a role in predicting $\mathrm{HCC}$ in patients with advanced liver disease. ${ }^{39-42}$

Unlike HCV, there are several studies which have assessed the impact of HBV non-IFN-based treatment on AFP values. ${ }^{34-36,43}$ Although the majority of patients assessed have been non-cirrhotic, the AFP values have been found to be consistently decreased alongside viral suppression. ${ }^{34-36,39,41,43}$ Interestingly, the pattern for normalization of AFP varies with different treatment, such as patients treated with entecavir experiencing a smooth, gradual reduction of AFP with a shorter period of AFP normalization (mean follow-up of 11.9 weeks) as compared to patients treated with pegylated-IFN experiencing a more fluctuating pattern with longer time of AFP normalization (mean follow-up of 22.3 weeks). ${ }^{36}$ However, complete
Table 5. Multivariate model of baseline labs and changes in AFP score

\begin{tabular}{lll}
\hline Variable & OR $(95 \% \mathrm{CI})$ & $p$ \\
\hline AFP at baseline, $\mathrm{ng} / \mathrm{dL}$ & $1(0.997-1.002)$ & 0.753 \\
Platelet count, $10^{3} / \mu \mathrm{L}$ & $1.002(1-1.004)$ & 0.044 \\
AST, U/L & $1.003(1.001-1.005)$ & 0.009 \\
Total bilirubin, $\mathrm{mg} / \mathrm{dL}$ & $0.895(0.801-0.999)$ & 0.043 \\
\hline
\end{tabular}

Abbreviations: AFP, alpha-fetoprotein; AST, aspartate transaminase.

normalization of AFP does not consistently occur. ${ }^{36,43}$ For instance, one study including only patients with cirrhosis found $84.4 \%$ of treated patients had AFP normalization after 12 months of treatment, while the other patients had persistently elevated AFP without HCC up to 126 weeks of follow-up. ${ }^{36}$

The results of our study indicate a statistically significant reduction in AFP values after achievement of SVR in patients with HCV-related cirrhosis treated with DAAs. The reduction in AFP was noted also at the end of treatment (EOT). In addition, we demonstrated AFP reduction is maintained over time. The severity of liver disease assessed by MELD, FIB4 or APRI scores was not associated with reduction in AFP over time. Our study is the first study to the best of our knowledge to focus exclusively on patients with cirrhosis treated exclusively with all-oral DAAs. Interpretation of previous studies examining the association between achievement of SVR with HCV antiviral therapies are limited by heterogeneous population and the use of IFN. ${ }^{13,16,18,19,23,37,38}$ In most studies, the treated population included both cirrhotic and non-cirrhotic patients. ${ }^{13,16,18,19,23,37,38,44}$ In the single study published to date using all-oral DAAs, over $80 \%$ of the treated cohort were noncirrhotic. ${ }^{44}$

Liver inflammation likely increases AFP values in the absence of HCC. Elimination of the inflammation through

Table 4. Factors associated with AFP decrease between AFP reduction and non-reduction cohorts

\begin{tabular}{llll}
\hline Variable & No decrease in AFP $(n=11)$ & Decrease in AFP $(n=47)$ & $p$ \\
\hline Baseline AFP, $\mathrm{ng} / \mathrm{mL}$ & $3.5(2.4-6.3)$ & $8.4(4.8-16.5)$ & $1200000(394000-3712500)$ \\
Viral load & $2380000(1335000-3425000)$ & $104(67-145)$ & 0.917 \\
Platelet count, $10^{3} / \mathrm{LL}$ & $60.5(47.2-77.8)$ & $3.7(3.3-4.2)$ & 0.009 \\
Albumin, g/dL & $3.4(3.2-3.7)$ & $1.1(1.1-1.2)$ & 0.106 \\
INR & $1.2(1.2-1.3)$ & $66(40.2-95.8)$ & 0.103 \\
AST, U/L & $44.5(32.5-54.5)$ & $55.5(35-76.8)$ & 0.036 \\
ALT, U/L & $31.5(25-45)$ & $0.8(0.6-1.4)$ & 0.028 \\
Total bilirubin, $\mathrm{mg} / \mathrm{dL}$ & $2(1.7-2.8)$ & $104.5(76-155.8)$ & 0.018 \\
Serum creatinine, $\mathrm{mg} / \mathrm{dL}$ & $0.8(0.7-0.9)$ & $13.1(11.9-14.1)$ & 0.412 \\
Alkaline phosphatase, U/L & $89(81.8-115.2)$ & $9.7(7.5-11.4)$ & 0.473 \\
Hemoglobin, g/dL & $13.2(12.4-13.9)$ & $6.1(3.3-10.1)$ & 0.946 \\
MELD & $12.1(10-13.2)$ & $1.6(0.8-3.7)$ & 0.085 \\
FIB4 & $5.7(5.1-10.3)$ & $139.5(137.8-142)$ \\
APRI & $1.3(1.2-2.7)$ & 0.462 \\
Sodium & $138.5(134.2-139.8)$ & 0.76 \\
\hline
\end{tabular}

Abbreviations: AFP, alpha-fetoprotein; INR, international normalized ratio; AST, aspartate transaminase; ALT, alanine transaminase; MELD, model for end-stage liver disease; FIB4, fibrosis-4; APRI, AST to platelet ratio index. 
SVR should make AFP more specific for the diagnosis of HCC. Similar findings have been described in the context of HBV infection, in which ALT elevation correlates with AFP values. ${ }^{34,39}$ The normalization of AFP was observed not just at the EOT but was maintained up until 48 weeks after the EOT. Moreover, we are able to demonstrate that reduction of AFP occurred regardless of liver disease severity, as measured by the MELD, APRI and FIB4 scoring systems.

An important limitation in our study is that although we were able to demonstrate a significant decrease in AFP values after achievement of SVR, which was sustained over time, additional studies are required to clarify its newly recognized predictive ability for HCC. Moreover, there may be other factors that contribute to the lack of specificity of AFP for diagnosis, such as the presence of steatohepatitis. 8,45 Patients with concomitant liver disease were excluded from our cohort, thus potentially limiting the generalizability of our results to other populations. Another limitation in our study is that we do not have results for other biomarkers of HCC, such as AFP-L3 and des-gamma-carboxy prothrombin. ${ }^{46,47}$ Although these biomarkers are utilized in many parts of the world for HCC screening, they are not often used in the United States and are not included in the current HCC guidelines published by the AASLD. ${ }^{3}$

We believe the results of our study have important and strong clinical significance for a number of reasons. First, ours is one of only a few studies to assess the changes in AFP in an exclusive population of patients with HCV-related cirrhosis. Second, our study is the first to exclusively evaluate the changes of AFP with DAAs, while others have focused only on using IFN-based therapy. Third, the results of our study have important clinical implications for the utility of AFP for HCC screening. Additional studies are needed to confirm the role of AFP in patients in HCC screening after achievement of SVR.

\section{Conflict of interest}

The authors have no conflict of interests related to this publication.

\section{Author contributions}

Study concept and design (KN, SS), acquisition of data (KN, $\mathrm{MJ}, \mathrm{NM}, \mathrm{CW}, \mathrm{AF})$, analysis and interpretation of data $(\mathrm{KN}, \mathrm{MJ}$, JG, DE, GC, FAD, MME, SHBH, SS), drafting of the manuscript (KN, MJ, SS), critical revision of the manuscript for important intellectual content (GC, FAD, MME, SHBH, SS), statistical analysis (JG, DE), administrative, technical, or material support, study supervision (DE, SS).

\section{References}

[1] El-Serag HB, Marrero JA, Rudolph L, Reddy KR. Diagnosis and treatment of hepatocellular carcinoma. Gastroenterology 2008;134:1752-1763. doi: 10. 1053/j.gastro.2008.02.090.

[2] El-Serag HB. Hepatocellular carcinoma. N Engl J Med 2011;365:1118-1127. doi: 10.1056/NEJMra1001683.

[3] Bruix J, Sherman M. American Association for the Study of Liver Diseases. Management of hepatocellular carcinoma: an update. Hepatology 2011;53: 1020-1022. doi: 10.1002/hep.24199.

[4] Zhang BH, Yang BH, Tang ZY. Randomized controlled trial of screening for hepatocellular carcinoma. J Cancer Res Clin Oncol 2004;130:417-422. doi: 10.1007/s00432-004-0552-0.

[5] Chen JG, Parkin DM, Chen QG, Lu JH, Shen QJ, Zhang BC, et al. Screening for liver cancer: results of a randomised controlled trial in Qidong, China. J Med Screen 2003;10:204-209. doi: 10.1258/096914103771773320.
[6] Mittal S, Kanwal F, Ying J, Chung R, Sada YH, Temple S, et al. Effectiveness of surveillance for hepatocellular carcinoma in clinical practice: A United States cohort. J Hepatol 2016;65:1148-1154. doi: 10.1016/j.jhep.2016.07.025.

[7] Davila JA, Henderson L, Kramer JR, Kanwal F, Richardson PA, Duan Z, et al. Utilization of surveillance for hepatocellular carcinoma among hepatitis $C$ virus-infected veterans in the United States. Ann Intern Med 2011;154: 85-93. doi: 10.7326/0003-4819-154-2-201101180-00006.

[8] Bloomer JR, Waldmann TA, McIntire KR, Klatskin G. alpha-fetoprotein in noneoplastic hepatic disorders. JAMA 1975;233:38-41. doi: 10.1001/jama. 1975.03260010040018

[9] Ruoslahti E, Seppälä M. Normal and increased alpha-fetoprotein in neoplastic and non-neoplastic liver disease. Lancet 1972;2:278-279. doi: 10.1016/ S0140-6736(72)91711-4.

[10] Sakurai T, Marusawa H, Satomura S, Nabeshima M, Uemoto S, Tanaka K, et al. Lens culinaris agglutinin-A-reactive alpha-fetoprotein as a marker for liver atrophy in fulminant hepatic failure. Hepatol Res 2003;26:98-105. doi: 10.1016/S1386-6346(03)00013-5.

[11] Taketa K. Alpha-fetoprotein: reevaluation in hepatology. Hepatology 1990; 12:1420-1432. doi: 10.1002/hep.1840120625.

[12] Di Bisceglie AM, Sterling RK, Chung RT, Everhart JE, Dienstag JL, Bonkovsky $\mathrm{HL}$, et al. Serum alpha-fetoprotein levels in patients with advanced hepatitis $\mathrm{C}$ : results from the HALT-C Trial. J Hepatol 2005;43:434-441. doi: 10.1016/j. jhep.2005.03.019.

[13] Chen TM, Huang PT, Tsai MH, Lin LF, Liu CC, Ho KS, et al. Predictors of alpha-fetoprotein elevation in patients with chronic hepatitis $\mathrm{C}$, but not hepatocellular carcinoma, and its normalization after pegylated interferon alfa 2a-ribavirin combination therapy. J Gastroenterol Hepatol 2007;22: 669-675. doi: 10.1111/j.1440-1746.2007.04898.x

[14] Murashima S, Tanaka M, Haramaki M, Yutani S, Nakashima Y, Harada K, et al. A decrease in AFP level related to administration of interferon in patients with chronic hepatitis C and a high level of AFP. Dig Dis Sci 2006;51:808-812. doi: 10.1007/s10620-006-3211-2.

[15] Tamura Y, Yamagiwa S, Aoki Y, Kurita S, Suda T, Ohkoshi S, et al. Serum alpha-fetoprotein levels during and after interferon therapy and the development of hepatocellular carcinoma in patients with chronic hepatitis C. Dig Dis Sci 2009;54:2530-2537. doi: 10.1007/s10620-008-0642-y.

[16] Arase Y, Ikeda K, Suzuki F, Suzuki Y, Kobayashi M, Akuta N, et al. Prolongedinterferon therapy reduces hepatocarcinogenesis in aged-patients with chronic hepatitis C. J Med Virol 2007;79:1095-1102. doi: 10.1002/jmv. 20866.

[17] Asahina $Y$, Tsuchiya $K$, Tamaki N, Hirayama I, Tanaka T, Sato M, et al. Effect of aging on risk for hepatocellular carcinoma in chronic hepatitis $C$ virus infection. Hepatology 2010;52:518-527. doi: 10.1002/hep.23691.

[18] Asahina Y, Tsuchiya K, Nishimura T, Muraoka M, Suzuki Y, Tamaki N, et al. $\alpha$-fetoprotein levels after interferon therapy and risk of hepatocarcinogenesis in chronic hepatitis C. Hepatology 2013;58:1253-1262. doi: 10.1002/hep. 26442.

[19] Tachi Y, Hirai T, Ishizu Y, Honda T, Kuzuya T, Hayashi K, et al. $\alpha$-fetoprotein levels after interferon therapy predict regression of liver fibrosis in patients with sustained virological response. J Gastroenterol Hepatol 2016;31: 1001-1008. doi: 10.1111/jgh.13245.

[20] Osaki Y, Ueda Y, Marusawa H, Nakajima J, Kimura T, Kita R, et al. Decrease in alpha-fetoprotein levels predicts reduced incidence of hepatocellular carcinoma in patients with hepatitis $\mathrm{C}$ virus infection receiving interferon therapy: a single center study. J Gastroenterol 2012;47:444-451. doi: 10. 1007/s00535-011-0505-8.

[21] El-Serag HB, Kramer J, Duan Z, Kanwal F. Epidemiology and outcomes of hepatitis C infection in elderly US Veterans. J Viral Hepat 2016;23:687-696. doi: $10.1111 /$ jvh.12533.

[22] El-Serag HB, Kanwal F, Richardson P, Kramer J. Risk of hepatocellular carcinoma after sustained virological response in Veterans with hepatitis $C$ virus infection. Hepatology 2016;64:130-137. doi: 10.1002/hep.28535.

[23] Takayama K, Furusyo N, Ogawa E, Ikezaki H, Shimizu M, Murata M, et al. Direct-acting antiviral-based triple therapy on alpha-fetoprotein level in chronic hepatitis C patients. World J Gastroenterol 2015;21:4696-4706. doi: $10.3748 /$ wjg.v21.i15.4696.

[24] El Kassas M, Elbaz T, Hafez E, Esmat G. Safety of direct antiviral agents in the management of hepatitis C. Expert Opin Drug Saf 2016;15:1643-1652. doi: 10.1080/14740338.2017.1240781.

[25] Pol S, Corouge M, Sogni P. Oral antiviral therapies for chronic hepatitis C infection. Ther Adv Infect Dis 2013;1:107-116. doi: 10.1177/2049936 113488359.

[26] Feld J], Foster GR. Second generation direct-acting antivirals - Do we expect major improvements? J Hepatol 2016;65:S130-S142. doi: 10.1016/j.jhep. 2016.07.007.

[27] Papudesu C, Kottilil S, Bagchi S. Elbasvir/grazoprevir for treatment of chronic hepatitis C virus infection. Hepatol Int 2016. doi: 10.1007/s12072-0169761-2. 
[28] Kamath PS, Wiesner RH, Malinchoc M, Kremers W, Therneau TM, Kosberg CL, et al. A model to predict survival in patients with end-stage liver disease. Hepatology 2001;33:464-470. doi: 10.1053/jhep.2001.22172.

[29] Kim WR, Biggins SW, Kremers WK, Wiesner RH, Kamath PS, Benson JT, et al. Hyponatremia and mortality among patients on the liver-transplant waiting list. N Engl J Med 2008;359:1018-1026. doi: 10.1056/NEJMoa0801209.

[30] Sterling RK, Lissen E, Clumeck N, Sola R, Correa MC, Montaner J, et al. Development of a simple noninvasive index to predict significant fibrosis in patients with HIV/HCV coinfection. Hepatology 2006;43:1317-1325. doi: $10.1002 /$ hep. 21178 .

[31] Lin ZH, Xin YN, Dong QJ, Wang Q, Jiang XJ, Zhan SH, et al. Performance of the aspartate aminotransferase-to-platelet ratio index for the staging of hepatitis C-related fibrosis: an updated meta-analysis. Hepatology 2011; 53:726-736. doi: 10.1002/hep.24105.

[32] Tomasi TB Jr. Structure and function of alpha-fetoprotein. Annu Rev Med 1977;28:453-465. doi: 10.1146/annurev.me.28.020177.002321.

[33] Gitlin D. Normal biology of alpha-fetoprotein. Ann N Y Acad Sci 1975;259: 7-16. doi: 10.1111/j.1749-6632.1975.tb25397.x.

[34] Yamada R, Hiramatsu N, Oze T, Morishita N, Harada N, Yakushijin T, et al. Impact of alpha-fetoprotein on hepatocellular carcinoma development during entecavir treatment of chronic hepatitis B virus infection. J Gastroenterol 2015;50:785-794. doi: 10.1007/s00535-014-1010-7.

[35] Shim JJ, Kim JW, Lee CK, Jang JY, Kim BH. Oral antiviral therapy improves the diagnostic accuracy of alpha-fetoprotein levels in patients with chronic hepatitis B. J Gastroenterol Hepatol 2014;29:1699-1705. doi: 10.1111/jgh. 12612.

[36] Luo K, Liu Z, Karayiannis P. Effect of antiviral treatment on alfa-fetoprotein levels in HBV-related cirrhotic patients: early detection of hepatocellular carcinoma. J Viral Hepat 2010;17:511-517. doi: 10.1111/j.1365-2893. 2009.01208.x.

[37] Oze T, Hiramatsu N, Yakushijin T, Miyazaki M, Yamada A, Oshita M, et al. Post-treatment levels of $\alpha$-fetoprotein predict incidence of hepatocellular carcinoma after interferon therapy. Clin Gastroenterol Hepatol 2014;12: 1186-1195. doi: 10.1016/j.cgh.2013.11.033.

[38] El Raziky M, Attia D, El Akel W, Shaker O, Khatab H, Abdo S, et al. Hepatic fibrosis and serum alpha-fetoprotein (AFP) as predictors of response to HCV treatment and factors associated with serum AFP normalisation after treatment. Arab J Gastroenterol 2013;14:94-98. doi: 10.1016/j.ajg.2013. 08.005 .
[39] Kim GA, Seock CH, Park JW, An J, Lee KS, Yang JE, et al. Reappraisal of serum alpha-foetoprotein as a surveillance test for hepatocellular carcinoma during entecavir treatment. Liver Int 2015;35:232-239. doi: 10.1111/liv.12516.

[40] Durazo FA, Blatt LM, Corey WG, Lin JH, Han S, Saab S, et al. Des-gammacarboxyprothrombin, alpha-fetoprotein and AFP-L3 in patients with chronic hepatitis, cirrhosis and hepatocellular carcinoma. J Gastroenterol Hepatol 2008;23:1541-1548. doi: 10.1111/j.1440-1746.2008.05395.x.

[41] Wong GL, Chan HL, Tse YK, Chan HY, Tse CH, Lo AO, et al. On-treatment alpha-fetoprotein is a specific tumor marker for hepatocellular carcinoma in patients with chronic hepatitis B receiving entecavir. Hepatology 2014; 59:986-995. doi: 10.1002/hep.26739.

[42] Lin YJ, Lee MH, Yang HI, Jen CL, You SL, Wang LY, et al. Predictability of liverrelated seromarkers for the risk of hepatocellular carcinoma in chronic hepatitis B patients. PLoS One 2013;8:e61448. doi: 10.1371/journal.pone. 0061448.

[43] Yang SW, Kim GH, Chung JW, Sohn HR, Lee SS, Hong S, et al. Prediction of risk for hepatocellular carcinoma by response of serum $\alpha$-fetoprotein to entecavir therapy. J Gastroenterol Hepatol 2015;30:1175-1182. doi: 10.1111 /jgh.12921.

[44] Miyaki E, Imamura M, Hiraga N, Murakami E, Kawaoka T, Tsuge M, et al. Daclatasvir and asunaprevir treatment improves liver function parameters and reduces liver fibrosis markers in chronic hepatitis $C$ patients. Hepatol Res 2016;46:758-764. doi: 10.1111/hepr.12621.

[45] Xu P, Xu CF, Wan XY, Yu CH, Shen C, Chen P, et al. Association between serum alpha-fetoprotein levels and fatty liver disease: a cross-sectional study. World J Gastroenterol 2014;20:11865-11870. doi: 10.3748/wjg.v20.i33. 11865.

[46] Toyoda H, Kumada T, Tada T, Kaneoka $Y$, Maeda A, Kanke F, et al. Clinical utility of highly sensitive Lens culinaris agglutinin-reactive alpha-fetoprotein in hepatocellular carcinoma patients with alpha-fetoprotein $<20 \mathrm{ng} / \mathrm{mL}$. Cancer Sci 2011;102:1025-1031. doi: 10.1111/j.1349-7006.2011. 01875.x.

[47] Sterling RK, Jeffers L, Gordon F, Venook AP, Reddy KR, Satomura S, et al. Utility of Lens culinaris agglutinin-reactive fraction of alpha-fetoprotein and des-gamma-carboxy prothrombin, alone or in combination, as biomarkers for hepatocellular carcinoma. Clin Gastroenterol Hepatol 2009;7:104-113. doi: $10.1016 /$ j.cgh.2008.08.041. 